\title{
Evaluación de la incidencia de los compo- nentes formales del lenguaje visual en la elaboración de ilustraciones: un estudio con estudiantes en formación inicial docente
}

\author{
ANA MALDONADO FUENTES* \\ Universidad del Bío-Bío - Chile \\ FRANCISCO RODRÍGUEZ ALVEAL** \\ Universidad del Bío-Bío - Chile \\ PEDRO SANDOVAL RUBILAR*** \\ Universidad del Bío-Bío - Chile \\ Recibido el 19-01-19; primera evaluación el 02-12-19; \\ segunda evaluación el 13-02-20; aceptado el 20-02-20
}

\section{RESUMEN}

La alfabetización visual es un aprendizaje clave para la construcción de significados, por lo que el conocimiento de los componentes del lenguaje visual es un resultado esperado del currículo escolar. Sin embargo, existen escasos estudios que recojan evidencia empírica al respecto, en particular, en la población de futuros profesores. El presente estudio, de tipo exploratorio y con técnicas de análisis cuantitativas, indaga sobre cuáles de estos componentes tendrían mayor incidencia en la elaboración de textos de naturaleza visual, a partir de la evaluación de un corpus

\footnotetext{
* Académica del Departamento de Ciencias de la Educación de la Facultad de Educación y Humanidades de la Universidad del Bío-Bío, Chile. Profesora de Castellano. Licenciada en Estética. Magíster en Ciencias de la Educación. Líneas de investigación: Formación Inicial Docente, Evaluación de Aprendizaje y Comprensión Lectora. Correo electrónico: amaldonado@ubiobio.cl

** Académico del Departamento de Ciencias de la Educación de la Facultad de Educación y Humanidades de la Universidad del Bío-Bío, Chile. Profesor de Estado en Matemática. Magíster en Bioestadística. Académico en la Universidad de Concepción, Universidad de Chile, Universidad Católica de Temuco, Universidad Mayor y la Universidad del Bío-Bío. Líneas de investigación: Formación Inicial Docente, Teoría de Distribuciones y Didáctica de la Estadística. Correo electrónico: frodriguez@ubiobio.cl *** Académico del Departamento de Ciencias de la Educación de la Facultad de Educación y Humanidades de la Universidad del Bío-Bío, Chile. Doctor en Ciencias de la Educación. Académico, investigador y docente de Pregrado, Magíster y Doctorado en distintas universidades de Chile. Área de especialización e investigación: Currículo, Evaluación Curricular, Aprendizajes y Formación Inicial Docente. Correo electrónico: psandoval@ubiobio.cl
} 
de ilustraciones elaboradas por estudiantes en Formación Inicial Docente (FID) de una universidad del Consejo de Rectores de Chile. El proceso de investigación implementado permitió identificar el predominio del color, la composición y la representación visual, cuya evaluación podría potenciar aprendizajes en este ámbito.

Palabras clave: alfabetización visual, Formación Inicial Docente, Educación Estética, evaluación auténtica, evaluación de aprendizaje.

\section{Evaluation of the Incidence of the Formal Elements of Visual Language for Illustration Making: A Research with Students in Initial Teaching Training}

\section{Abstract}

In the learning process, visual literacy is key for the construction of meanings, and knowledge of the components of visual language is an expected outcome of the school curriculum. However, studies offering empirical evidence in this area are scarce, particularly from teaching students. This research of exploratory type and with quantitative analysis techniques, examines which of these components would have a greater impact on the elaboration of texts of a visual nature, based on the evaluation of a corpus of illustrations originally made by Early Teacher Training students at a university that is a member of the Board of Chancellors of Chilean Universities. The research process allowed us to identify the predominance of color, composition and visual representation, whose evaluation could enhance learning in this area.

Keywords: Visual Literacy, Initial Teacher Training, Aesthetic Education, Authentic Evaluation, Learning Evaluation

\section{Avaliaçáo da Incidência dos Elementos Formais da Linguagem Visual para Preparaçáo De Ilustraçóes: Um estudo com estudantes em Formaçáo Inicial de Professores}

\section{Resumo}

A alfabetização visual é uma aprendizagem chave para a construção de significados, de modo que o conhecimento dos componentes da linguagem visual é um resultado esperado do currículo escolar. Contudo, são escassos os estudos que coletam evidências empíricas a esse respeito, nomeadamente, na populaçáo de futuros professores. Este estudo, do tipo exploratório e com técnicas de análise quantitativa, pesquisa sobre quais desses componentes teriam maior impacto para a elaboração de um texto de natureza visual com base na avaliação de um corpus de ilustraçóes foram feitas por estudantes em Formação Inicial de Professores de uma universidade do Conselho de Reitores do Chile. O processo de pesquisa implementado permitiu identificar a predominância de cor, composição e representação visual durante sua avaliação, cuja avaliaçáo poderia melhorar o aprendizado nessa área.

Palavras-chave: Alfabetização Visual, Formação Inicial de Professores, Educação Estética, Avaliação autêntica, Avaliação de Aprendizagem 


\section{INTRODUCCIÓN Y CONTEXTUALIZACIÓN}

El siglo XXI es un mundo globalizado, diversificado y complejo, en el que se ofrecen diferentes modos semióticos de organizar los discursos (escrito, oral, sonoro, auditivo, espacial, gestual); los que al mismo tiempo se difunden en modalidades cada vez más tecnológicas y multimodales. Es así como la actual sociedad se caracteriza, porque «el soporte de la información evoluciona hacia los sistemas multimedia, con un elevado peso de la palabra escrita en algunos casos, pero con un peso creciente de la imagen en otros» (Pina, 2001, p. 112), por lo que se hace indispensable el procesamiento de información verbal como no verbal para la construcción de significados.

De lo anterior se deriva un renovado concepto de alfabetización que no solo se limita al lenguaje oral y escrito, sino que integra todas las manifestaciones comunicativas culturales y sociales en un espacio-tiempo determinado. En este sentido, la actualidad remite a una práctica social simbólica compleja, pues la comunicación suele organizarse de manera cada vez más multimodal, siendo lo visual un elemento clave para las prácticas comunicativas de la sociedad moderna, tal como se evidencia en el uso masivo de las redes sociales.

En ese contexto, lo visual resulta relevante no solo por razones estéticas, sino que el uso de este tipo de componentes contribuye a configurar códigos necesarios para la construcción de los significados, por lo que el alumnado requiere del desarrollo de habilidades de comunicación visual dentro del sistema escolar (Farías y Araya, 2014) para codificar y componer imágenes con sentido (Borges, 2012). Tal redefinición implica apropiarse de un concepto de aprendizaje que no se limite solamente a la decodificación del texto verbal - como lo era tradicionalmente-, sino que incorpore en forma explícita un trabajo de codificación y decodificación de textos multimodales, en los que lo visual constituye un elemento de importancia. Es así como García Matilla desde la década de 1990 ha planteado la necesidad de una educación para la imagen y con la imagen (García y Benítez, 1998), en que el sujeto conozca los lenguajes específicos como antesala para su uso didáctico en aula. Tan relevante ha sido esta visión desde las políticas públicas, que dentro de los estándares para la Formación Inicial Docente se sostiene que el futuro profesor será capaz de identificar los conceptos básicos del lenguaje visual, comprendiéndolo "como un lenguaje que puede ser enseñado" (Brodsky y Negrón, 2016, p. 18). Además, el uso del lenguaje visual y multimodal en un sentido amplio está presente en todas las asignaturas del currículo escolar de Educación Básica; por ejemplo, Ciencias Naturales, Historia, Geografía y Ciencias Sociales y Matemáticas (Mineduc, 2018). En consecuencia, implica 
un replanteamiento de la forma en que se aprende y se enseña los procesos de comunicación (Hernández, 2009), tomando en cuenta la función que tienen las imágenes en el aprendizaje y su rol en la cultura mediática; tal como se ha señalado en la literatura especializada y el currículum escolar vigente.

En consecuencia, el rol del profesor resulta clave para propiciar experiencias de aprendizaje que faciliten la comprensión de la alfabetización visual, favoreciendo una inserción actualizada en distintos campos, tales como las artes y las ciencias (Pagliarulo, 2013). De allí que resulte interesante preguntarse qué tan preparados se encuentran los docentes para interpretar e integrar el uso de los elementos constitutivos del lenguaje visual en sus prácticas de enseńanza. En particular, es necesario indagar sobre los conocimientos de los componentes formales del lenguaje visual que han ido construyendo los estudiantes de formación inicial docente (en adelante FID), población cuya línea de investigación es de desarrollo incipiente en el país (Cisternas, 2011), pues es sabido que para que el profesorado pueda desarrollar habilidades en su futuro profesional, requiere haberlas vivenciado previamente durante su formación (Comellas, 2000).

En coherencia, cabe preguntarse por los aprendizajes de los estudiantes FID acerca del lenguaje visual y los criterios que orienten su evaluación, para de esta forma contribuir al desarrollo de habilidades de alfabetización visual en el sistema educativo. Empero, son escasos los estudios empíricos en este ámbito, siendo, en general, indagaciones vinculadas a la educación artística o educación multimodal, de tipo caso único o con una cantidad reducida de participantes (García y Benitez, 1998; Correa, 2015; Sánchez Ruiz, 2017; García, 2018). Específicamente, el presente estudio se relaciona con la siguiente cuestión: ¿Cuáles son los componentes formales del lenguaje visual que tendrían mayor incidencia en la elaboración de un texto de naturaleza visual? En concreto, se describen resultados a partir del análisis de las ilustraciones de un cuento, cuyo guion literario y storyboard fueron elaborados en forma original por estudiantes de FID pertenecientes a una universidad regional del centro sur de Chile, adscrita al Consejo de Rectores de las Universidades Chilenas (CRUCH) ${ }^{1}$. Los datos provienen de una experiencia de investigación en docencia desarrollada interdisciplinariamente entre 2015 y 2017.

1 El Consejo de Rectores de las Universidades Chilenas (CRUCH) es una persona jurídica de derecho público, de administración autónoma, creado el 14 de agosto de 1954 (Ley No 11.575). Está integrado por los rectores de las veinticinco universidades públicas y tradicionales del país. 


\section{Marco teórico}

\subsection{Alfabetización visual}

La expresión alfabetización visual fue acuñada por John Debes en la década de 1960 y tiene un uso extendido en la literatura, «aunque no existe una definición acordada de manera única sobre lo que significa» (Salisbury y Styles, 2014, p. 56). No obstante, una de las que resalta en la literatura especializada es que la alfabetización visual:

[...] supone que tal como aprendemos las reglas básicas de la gramática, alfabeto, etc., que permiten que nos comuniquemos a través de la escritura, deberíamos también aprender las reglas elementales de la comunicación visual, sin que esto esté circunscrito a especialistas del área, tal como la enseñanza de la escritura no se restringe a los literatos (Ferreras y Vergilio, 2008, p. 250)

En otras palabras, esta puede ser entendida como un proceso de aprendizaje que sugiere la capacidad de leer una imagen pictórica, atendiendo a la representación y su contenido semántico (González, 1991). En tal caso, «la lectura de los textos icónicos supone un conocimiento previo de los elementos que constituyen el lenguaje visual y de la manera en la que se integran dichos elementos en la producción de mensajes»(Villa Orrego, 2008, p. 210). Estos permiten establecer relaciones entre lo representado y la realidad a la que se refiere, distinguiéndose entre otros, a nivel formal: la línea, el color, la forma, la textura, el plano y la proporcionalidad.

La utilidad de conocer los elementos formales del lenguaje visual radica en que al describir las representaciones visuales se puede develar el significado denotativo de la imagen, logrando una lectura literal. Más aún, si la elaboración de ilustraciones se complementa con elementos culturales, tales como época, autor, movimiento artístico, propósito comunicativo o contexto de producción, es posible llegar a un nivel connotativo o lectura inferencial. De allí que se sostenga que «la idea central reside en que alguien que conozca los mecanismos del lenguaje visual será capaz no solo de producir material visual, sino también de interpretar lo que se le muestra» (Ferreras y Vergilio, 2008 , p. 253), por lo que su enseñanza explícita adquiere una doble funcionalidad dentro de la educación escolar.

En particular, la interpretación de la información que emana de los elementos del código visual cobra relevancia en la literatura infantil, pues tal como afirma Colomer (2010), los formatos narrativos actuales ofrecen un trasvase de los elementos a la imagen, incorporándose las ilustraciones como un elemento más de la construcción de la historia, a diferencia de lo que tradicionalmente 
sucedía en que el texto la contaba y la imagen la ilustraba. Por lo que, tal como se mencionó anteriormente, su aprendizaje resulta de particular interés para el desarrollo profesional de los profesores de Educación Primaria. Sin embargo:

[...] desafortunadamente, en la mayoría de los casos, los docentes no han recibido como parte de su formación los referentes conceptuales suficientes para dimensionar el valor que tiene la imagen en los procesos de lecto-escritura, a lo que se suma la escasez de recursos didácticos que los orienten y apoyen en la tarea de enseñar a leer imágenes (Villa Orrego, 2008, p. 210)

Tomando en cuenta lo anterior, el presente estudio se focaliza en la identificación de los componentes formales del lenguaje visual que presentan mayor incidencia en la elaboración de ilustraciones; cuya producción es original por parte de estudiantes FID que han participado en una experiencia de investigación docente.

\subsection{Componentes del lenguaje visual}

Una de las ideas más consolidadas en la literatura, la cual explora los procesos de comunicación humana, es que todo lenguaje posee sus propios códigos; y el lenguaje visual no es la excepción. Adscribirse a esta premisa supone, entre otros aspectos, que los sujetos deben aprender los elementos formales propios del cada tipo de alfabetización para poder descodificar y codificar los mensajes (ya sean verbales, visuales, gestuales, etc.), en cuya representación se reflejan imágenes del mundo exterior o interior de los propios sujetos.

Así, por ejemplo, en el lenguaje verbal existen normas para el alfabeto y la distinción de grafemas, a partir de lo cual se transmiten mensajes haciendo uso de palabras y conceptos. Algo similar se observa en el lenguaje visual, siendo el punto, la línea, la forma (plana o volumétrica), el color y la textura elementos básicos que permiten construir la imagen visual.

Si bien los elementos mencionados anteriormente en sus diferentes combinaciones permiten dar origen a múltiples imágenes visuales, la literatura especializada ha documentado que cada uno de ellos, por sí solo, no permite comunicar ideas del mundo interior o exterior del sujeto. Al igual que lo que sucede con las palabras o conceptos en el lenguaje escrito, es necesario organizar y articular estos elementos en una unidad (la imagen visual) para comunicar las diversas ideas o sentimientos. Esto en el lenguaje visual recibe el nombre de composición.

Es por ello que, existe consenso en afirmar que tanto los elementos básicos como la composición en la imagen visual permiten la construcción de 
significados, nociones o conceptos, en coherencia con la especificidad del código visual. Por tanto, el acceso a una alfabetización que considere los aspectos formales y la composición serían claves para el desarrollo de los procesos de codificación y descodificación intrínsecos a la habilidad de comprensión del lenguaje visual. En este sentido, adherimos a la expectativa que es necesario que los futuros profesores del sistema escolar cuenten en su trayectoria formativa con experiencias de aprendizaje de alfabetización visual (Dondis, 2007), de modo que conozcan y manejen estos componentes (elementos formales y composición visual). Para ello, es oportuno determinar los criterios de evaluación, de manera tal que se facilite la valoración y retroalimentación del aprendizaje de estos componentes, bajo el supuesto de que su dominio está en directa relación con el desarrollo de las capacidades expresiva y comunicativa de los sujetos en este tipo de lenguaje.

Surge así el interés en estudiar el nivel de relevancia que tienen algunos elementos formales del lenguaje visual para comunicar ideas en un texto ilustrado. En este caso se trata de ilustraciones cuya elaboración también puede ser consignada como una tarea de evaluación auténtica. Es decir, productos creados en forma original con la intención de averiguar qué sabe o qué es capaz de hacer el estudiante (Ahumada, 2005), teniendo como foco de interés los aprendizajes en torno al color, la composición y la representación visual.

$\mathrm{Al}$ respecto, cabe precisar, en primer lugar, que el color desempeńa un papel importante en el sistema de organización de conceptos en el cerebro (Cuervo Díez, 2012) y es un elemento a través del cual se expresan sentimientos, sensaciones, deseos, etc. Al ser percibido, puede ser interpretado (los sujetos le dan sentido), por lo cual juega un rol relevante en la composición de la imagen y para la comunicación visual (Holzschlag, 2002). Adicionalmente, dada su naturaleza subjetiva, se sabe que los colores pueden tener interpretaciones diversas; sin embargo, es posible observar énfasis, pues dicho uso está mediatizado por elementos culturales y sociales. Así, por ejemplo, uno de los primeros exponentes en distinguir los colores básicos fue Aristóteles, al relacionarlos con los cuatro elementos: tierra, agua, fuego y cielo. Por otro lado, la teoría de Plutchik $(1965,1984)$ ha revelado tendencias en su interpretación vinculadas a las emociones, de lo que es posible desprender que los colores tienden a comunicar ciertas ideas, tales como: peligro, lejanía, ternura o amor, entre otras. Atendiendo a la temperatura del color, los colores fríos tienden a asociarse con las primeras ideas y los cálidos con las últimas. No obstante, dicha interpretación estaría supeditada al sujeto y al contexto general de la imagen; es decir, a la composición, lo que invita a considerarlo como un elemento formal no aislado de la misma en el presente estudio. 
En segundo término, en este caso se pone énfasis en capturar los aprendizajes que evidencian los futuros profesores en torno a la composición, dado que esta supone una forma de ordenar los elementos de la imagen como un todo estructurado. En otras palabras, cada elemento (línea, punto, trazo, color, etc.) conforman un todo unitario, que en conjunto configuran la idea, concepto o sentido de la imagen (Wong, 1998). En particular, en este caso, a partir de lo anterior, es posible afirmar que el encuadre y el equilibrio visual puedan ser visualizados como factores claves de la composición visual.

Finalmente, en tercer lugar, la representación visual puede ser entendida como la forma que permite transmitir un mensaje o el significado de la ilustración. Esta se diferencia del fondo (soporte) como contornos compactos que ocupan ese espacio del soporte donde se elabora la ilustración (Rowden, 2003). En razón de lo anterior, en el presente estudio se abordará dicho aspecto mediante la evaluación de la iconicidad de la imagen o el objeto creado en la imagen (caracterización, temporalidad, etc.).

\section{Metodología}

\subsection{Objetivos del estudio}

La finalidad general del trabajo es identificar los componentes formales del lenguaje visual que tendrían mayor incidencia en la elaboración de textos de naturaleza visual. Para el logro de este propósito, se espera describir desempeńos asociados al uso de los componentes formales del lenguaje visual en un corpus de ilustraciones elaboradas por estudiantes FID, a partir de las cuales puntualizar los que tienen mayor predominancia. En un sentido práctico y pedagógico, acceder a esta información permitiría orientar el aprendizaje en el uso de los componentes formales del lenguaje visual con criterios para su evaluación y así contribuir al mejoramiento de las habilidades de alfabetización visual de los futuros profesores.

\subsection{Diseño metodológico}

Mediante un diseño correlacional, el estudio se aproxima a la alfabetización visual desde los componentes formales del lenguaje visual y su caracterización en ilustraciones. Dado su carácter no experimental y exploratorio, no pretende generalizar resultados (Sautu, Boniolo, Dalle y Elbert, 2005), sino que dar cuenta de cuáles son aquellos componentes que contribuyen en mejor forma a la elaboración de estos productos, cuyo corpus ha sido generado por estudiantes de FID. 
Metodológicamente, se emplean técnicas cuantitativas para el análisis de datos (en este caso, las ilustraciones). Se utilizan métodos descriptivos numéricos (promedio, desviación estándar y porcentajes) para determinar la presencia de niveles y factores. Asimismo, se utilizaron métodos inferenciales (coeficiente de correlación de Pearson, modelo de regresión lineal múltiple) que permitieran formular conclusiones ajustadas a los propósitos del estudio. Para vigilar la consistencia interna de los instrumentos aplicados, se utilizó el Alfa de Cronbach (se determinó como criterio de rigurosidad coeficiente $\alpha>0,7)$ y el test Kaiser, Meyer y Olkin (KMO). El nivel de significación para encontrar diferencias estadísticas entre los promedios fue del 5\%. Con relación al procesamiento de la información, se utilizó el software Statistical Package for the Social Sciences (SPSS), en la versión 21, de acceso institucional.

\subsection{Grupo de estudio}

La población objeto de estudio la constituyen estudiantes de FID de Pedagogía en Educación Básica de una universidad del Consejo de Rectores (CRUCH) localizada en el centro sur de Chile. Para la selección de los participantes en esta investigación en docencia, se consideró una muestra aleatoria simple con una varianza máxima, un error de no más del $9 \%$, un nivel de confianza del $95 \%$ y un factor de corrección por población finita. Es así como el tamaño de la muestra fue de 36 estudiantes. El grupo, en su mayoría, es de género femenino $(94,4 \%)$ y el $100 \%$ de los casos pertenecen a la cohorte 2015 . Todos los sujetos participaron del estudio de manera voluntaria, dando el consentimiento informado (Meo, 2010), en coherencia con la política institucional. De esta forma, en la presentación de resultados, las unidades de análisis son citadas mediante un código alfanumérico que representa el grupo de trabajo, según acuerdo de anonimato de los participantes.

\subsection{Instrumento}

La unidad de análisis es el corpus de 22 ilustraciones, producciones originales de los estudiantes del grupo de estudio, procesado como datos visuales. Para efectos de evaluar estos productos, se diseñó un instrumento ad hoc (ver Tabla 1), que permitiera identificar niveles de logro en relación con el uso de elementos formales del lenguaje visual en dichas ilustraciones. Se trata de una escala Likert con cuatro alternativas ( $1=$ Insuficiente, $2=$ Aceptable, $3=$ Bueno y $4=$ Muy Bueno). Se toma esta opción metodológica dado que «las escalas ayudan a registrar el grado de desarrollo que un estudiante logra en relación con un proceso o producto» (Anijovic y González, 2013, p. 43); y se vigila 
así que el diseño del instrumento sea coherente con las orientaciones del enfoque de la evaluación auténtica (Ahumada, 2005).

Tabla 1. Tabla de especificaciones - Instrumento de evaluación alfabetización visual

\begin{tabular}{|c|c|c|}
\hline Componentes & Criterio & Descripción \\
\hline \multirow{3}{*}{ Color } & $\begin{array}{l}\text { Armonía de } \\
\text { colores }\end{array}$ & $\begin{array}{l}\text { Utiliza armonía de colores para diferenciar } \\
\text { elementos dentro de la composición. }\end{array}$ \\
\hline & $\begin{array}{l}\text { Contraste de } \\
\text { colores }\end{array}$ & $\begin{array}{l}\text { Utiliza contraste de colores opuestos para resaltar } \\
\text { elementos importantes dentro de la composición. }\end{array}$ \\
\hline & $\begin{array}{l}\text { Efecto de } \\
\text { profundidad }\end{array}$ & $\begin{array}{l}\text { Elabora fondo de las láminas utilizando } \\
\text { aplicación de color según perspectiva atmosférica } \\
\text { para dar énfasis a la profundidad de la escena. }\end{array}$ \\
\hline \multirow{3}{*}{ Composición } & $\begin{array}{l}\text { Proporcionalidad } \\
\text { de elementos }\end{array}$ & $\begin{array}{l}\text { Considera diversas proporciones en la } \\
\text { construcción de los elementos que permita } \\
\text { diferenciarlos por importancia o profundidad. }\end{array}$ \\
\hline & Encuadres & $\begin{array}{l}\text { Utiliza varios encuadres para representar las } \\
\text { distintas escenas en coherencia con el mensaje } \\
\text { representado. }\end{array}$ \\
\hline & Equilibrio visual & $\begin{array}{l}\text { Elabora una composición equilibrada } \\
\text { considerando la inclusión de elementos dentro de } \\
\text { los cuatro puntos fuertes del plano-imagen. }\end{array}$ \\
\hline \multirow{3}{*}{$\begin{array}{l}\text { Representación } \\
\text { visual }\end{array}$} & $\begin{array}{l}\text { Caracterización } \\
\text { de personajes }\end{array}$ & $\begin{array}{l}\text { Caracteriza visualmente a los personajes y rol en } \\
\text { la historia a través de la vestimenta, tamaños y/o } \\
\text { gestos. }\end{array}$ \\
\hline & $\begin{array}{l}\text { Caracterización } \\
\text { temporoespacial }\end{array}$ & $\begin{array}{l}\text { Caracteriza visualmente los objetos en orden } \\
\text { temporoespacial. }\end{array}$ \\
\hline & Pertinencia & $\begin{array}{l}\text { Los elementos se configuran en relación con el } \\
\text { contenido general del mensaje representado. }\end{array}$ \\
\hline
\end{tabular}

La evaluación auténtica se realizó asignando puntaje según el nivel de logro en cada criterio, cuyos contenidos y definiciones fueron validados en consenso por académicos de Diseńo Gráfico, a partir de la propuesta conceptual de Ospina (2011). Estos responden a tres componentes/factores: color, composición y representación visual. Cabe señalar que el análisis psicométrico del instrumento arrojó post aplicación a un Alpha de Cronbach de 0,81 y un índice $\mathrm{KMO}$ de 0,67 , valores que según la literatura especializada son considerados como «buenos» en las primeras fases de investigación (Nunnally, 1987). 


\section{Resultados}

Los resultados se informan en coherencia con los propósitos, evaluando cuáles de los componentes formales del lenguaje visual (ver Tabla 1) tendrían mayor incidencia en la elaboración de textos de naturaleza visual. En la Tabla 2 , se presentan los porcentajes de desempeño obtenidos, distinguiendo los resultados, según cada criterio de valoración. Los resultados muestran que la mayor frecuencia de desempeño logrado porcentual promedio se observa en el componente de «Representación visual» con un 71,6\%, y el menor en el componente «Composición», que obtiene un 66,3\%. En este último caso, el resultado es comparativamente más homogéneo, pues presenta la desviación estándar más pequeña (D.E.=18,2). En los criterios específicos, los valores promedio no superan el 77,3\% de logro en el total de sujetos evaluados, siendo «Pertinencia» el aspecto que obtiene mayor porcentaje de logro.

Tabla 2. Porcentajes de logro en los factores y criterios de codificación visual

\begin{tabular}{llcl}
\hline \multicolumn{1}{c}{ Componentes } & \multicolumn{1}{c}{ Criterio de evaluación } & \% promedio & \% promedio \\
\hline \multirow{4}{*}{ Color } & Armonía de colores & $67,0 \pm 17,5$ & \\
& Contraste de colores & $71,6 \pm 17,3$ & $67,4 \pm 18,4$ \\
& Efecto de profundidad & $63,6 \pm 19,6$ & \\
\hline \multirow{3}{*}{ Composición } & Proporcionalidad de elementos & $68,2 \pm 21,6$ & \\
& Encuadres & $62,5 \pm 18,1$ & $66,3 \pm 18,2$ \\
& Equilibrio visual & $68,2 \pm 13,4$ & \\
\hline \multirow{3}{*}{ Representación visual } & Caracterización de personajes & $72,7 \pm 21,1$ & \\
& Certinencia & $77,3 \pm 16,7$ & \\
\hline
\end{tabular}

Promedio \pm Desviación estándar

En la Tabla 3 se presentan los cálculos de correlaciones entre color, composición y representación visual, para identificar cuál o cuáles de ellos tiene mayor incidencia en la elaboración del corpus de las ilustraciones realizadas. En dicha tabla, se puede observar que «Armonía» $\mathrm{y}$ "Contraste de colores» no podrían ser considerados como factores aislados, lo que coincide con la teoría, dado que los colores pueden ser realzados o disminuidos para diferenciar y/o resaltar elementos dentro de una composición. 
Tabla 3. Correlación entre aspectos de color y equilibrio visual

\begin{tabular}{lccc}
\hline & Contraste de colores & Efecto de profundidad & Equilibrio visual \\
\hline Armonía de colores & 0,24 & $0,60^{* *}$ & 0,21 \\
Contraste de colores & & 0,33 & $0,63^{* *}$ \\
\hline
\end{tabular}

${ }^{*}$ Diferencias significativas al $5 \%$ - **Diferencias significativas al $1 \%$.

De la Tabla 3 se desprende que «Armonía de colores» se correlaciona de manera significativa con «Efecto de profundidad» $(\mathrm{r}=0,60, \mathrm{p}$-value $<0,01)$. Lo anterior puede ser explicado dado que la diferenciación de elementos dentro de una composición se asocia a la aplicación del color, con lo cual es posible dar énfasis a la profundidad de la escena; situación que se ejemplifica en la Figura 1. Por otro lado, se observa una correlación estadísticamente significativa entre «Contraste de colores» $\mathrm{y}$ «Equilibrio visual» $(\mathrm{r}=0,63$, $\mathrm{p}$-value $<0,01)$, aspectos que tributan a la composición de la representación visual. Por ejemplo, en la Figura 2, se visualiza la inclusión de elementos dentro de los cuatro puntos fuertes del plano-imagen, junto con el tratamiento de luz y sombra que permite resaltar aspectos centrales en la composición.

\section{Figura 1. Color y efecto de profundidad}

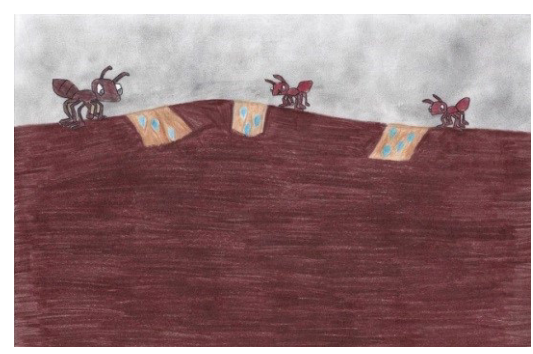

Estudiantes FID-Grupo 17 (2015)

Las hormigas egoistas [Imagen 3]. Sala de clases. Chillán
Figura 2. Contraste y equilibrio visual

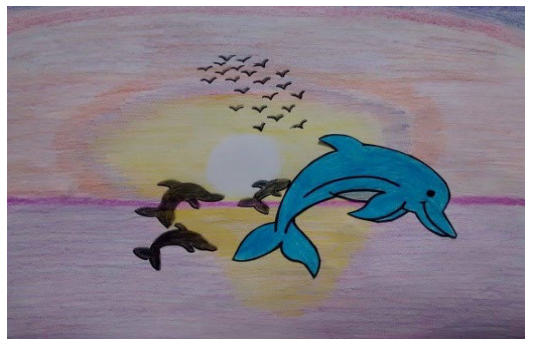

Estudiantes FID-Grupo 14 (2015) La curiosidad por los aires [Imagen 5]. Sala de clases. Chillán

Fuente: Registro de estudiantes Proyecto Innovación en Docencia (junio 2015).

Otro aspecto evaluado en esta ocasión fue la composición, considerando la proporcionalidad de elementos, el uso de variedad de encuadres y el equilibrio visual. Como se observa en la Tabla 4, el criterio «Encuadres» se correlaciona significativamente con «Caracterización de personajes» $(r=0,53)$ y 
«Equilibrio visual» $(\mathrm{r}=0,44)$. Por otro lado, «Proporcionalidad de elementos» se correlaciona significativamente con «Caracterización de personajes» $(r=0,67)$, «Caracterización temporoespacial» $(r=0,51)$ y «Pertinencia» $(r=0,46)$.

Tabla 4. Índices de correlación entre aspectos de composición y otras variables

\begin{tabular}{lccccc}
\hline & $\begin{array}{c}\text { Proporcio- } \\
\text { nalidad de } \\
\text { elementos }\end{array}$ & $\begin{array}{c}\text { Equilibrio } \\
\text { visual }\end{array}$ & $\begin{array}{c}\text { Caracteri- } \\
\text { zación de } \\
\text { personajes }\end{array}$ & $\begin{array}{c}\text { Caracteriza- } \\
\text { ción espacio- } \\
\text { temporal }\end{array}$ & Pertinencia \\
\hline Encuadres & 0,36 & $0,44^{*}$ & $0,53^{*}$ & 0,25 & 0,11 \\
$\begin{array}{l}\text { Proporcionalidad } \\
\text { de elementos }\end{array}$ & & 0,22 & $0,67^{* *}$ & $0,51^{*}$ & $0,46^{*}$ \\
\hline
\end{tabular}

${ }^{*}$ Diferencias significativas al $5 \%,{ }^{* *}$ Diferencias significativas al $1 \%$.

Las Figuras 3 y 4 ejemplifican ilustraciones en las cuales la composición favorece la comprensión del mensaje. Se trata de la caracterización de personajes (a través de la vestimenta, tamaño y/o gestos), valorados con desempeño «Bueno» $\mathrm{o}$ «Muy bueno» en criterios de «Encuadre» y/o «Proporcionalidad de elementos».

Figura 3. Caracterización de personajes

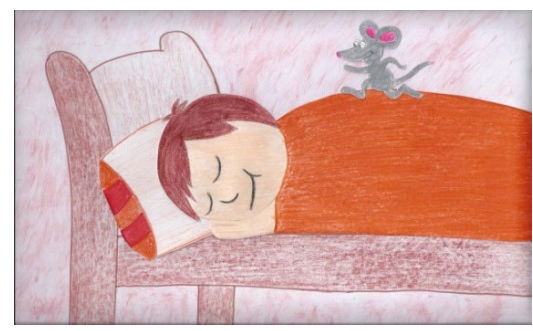

Estudiantes FID-Grupo 3 (2015) El diente de Agustin [Imagen 5]. Sala de clases. Chillán
Figura 4. Caracterización de personajes

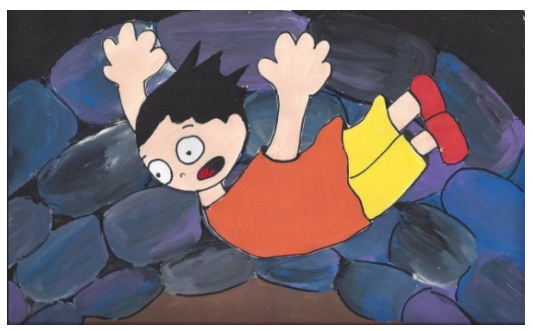

Estudiantes FID-Grupo 2 (2015)

Diego el niño desobediente [Imagen 4].

Sala de clases. Chillán

Fuente: Registro de estudiantes Proyecto Investigación en Docencia (junio 2015).

Respecto de la representación visual, en la Tabla 5 se evidencian los índices de correlación entre «Caracterización de personajes», "Caracterización temporoespacial» $\mathrm{y}$ los criterios de «Color» $\mathrm{y}$ «Composición». 
Tabla 5. Índices de correlación entre aspectos de caracterización y otras variables

\begin{tabular}{lccccc}
\hline & $\begin{array}{c}\text { Armonía } \\
\text { de colores }\end{array}$ & $\begin{array}{c}\text { Contraste } \\
\text { de colores }\end{array}$ & $\begin{array}{c}\text { Efecto de } \\
\text { profundidad }\end{array}$ & $\begin{array}{c}\text { Proporcionalidad } \\
\text { de elementos }\end{array}$ & Encuadres \\
\hline $\begin{array}{l}\text { Caracterización } \\
\text { de personajes }\end{array}$ & 0,28 & 0,16 & 0,12 & $0,67^{* *}$ & $0,53^{*}$ \\
$\begin{array}{l}\text { Caracterización } \\
\text { temporoespacial }\end{array}$ & $0,56^{* *}$ & $0,47^{*}$ & $0,54^{* *}$ & $0,51^{*}$ & 0,25 \\
\hline
\end{tabular}

${ }^{*}$ Diferencias significativas al $5 \%$. ${ }^{*}$ Diferencias significativas al $1 \%$.

Tal como se informa en la Tabla 5, se observa alta correlación en la mayoría de los factores vinculados a la caracterización del ambiente visual (temporal y espacial), en particular «Armonía de colores» $\mathrm{y}$ "Efecto de profundidad» con niveles de significancia al 0,01 . Por su parte, «Contraste de colores» $\mathrm{y}$ «Proporcionalidad de elementos» correlacionan positivamente de manera bilateral con este tipo de caracterización, aunque disminuyendo el nivel de significancia a 0,05.

Por otro lado, un aspecto que se relaciona bilateralmente con ambos tipos de caracterización es la «Proporcionalidad de elementos», con valores de $0,67^{* *}$ para el caso de los personajes y $0,51^{*}$ para el ambiente temporoespacial. Cabe señalar que esta variable presenta un índice de correlación bilateral de $0,54^{* *}$ (nivel de 0,01 ) con «Efecto de profundidad»; lo que coincide con la definición operacional del estudio, en que la proporcionalidad «considera diversas proporciones en la construcción de los elementos que permita diferenciarlos por importancia o profundidad». A continuación, se presentan figuras a modo de ejemplo.

Figura 5. Proporcionalidad de elementos

Figura 6. Ambiente temporoespacial

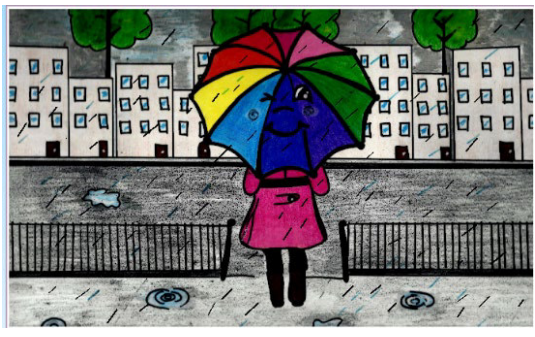

Estudiantes FID-Grupo 9 (2015)

El sueño realizado del paraguas negro

[Imagen 6]. Sala de clases. Chillán

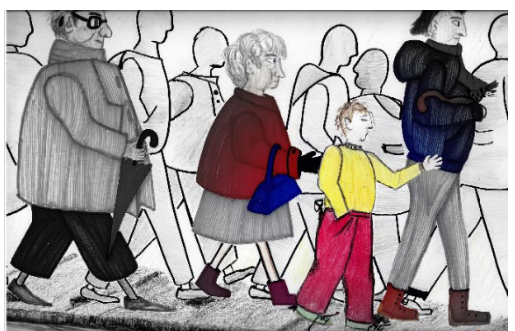

Estudiantes FID-Grupo 6 (2015) Él es Pedro [Imagen 1]. Sala de clases. Chillán 
Finalmente, para analizar cuál de estos elementos de alfabetización visual tiene mayor incidencia, se procedió a calcular el coeficiente Beta y la regresión lineal entre los factores (consideradas variables independientes) y el puntaje total obtenido por los productos evaluados. En otras palabras, se utiliza el método de análisis "hacia adelante», dado que permite identificar progresivamente cuál de las dimensiones tiene más peso para explicar el puntaje total obtenido. Mediante el procedimiento de selección de variables stepwise se ajustó un modelo de regresión lineal múltiple el cual permite capturar un alto porcentaje de la variabilidad total $\left(\mathrm{R}^{2}=0,98\right)$. En la Tabla 6 , se entregan los predictores y sus aportes en el modelo propuesto y ajustado.

Tabla 6. Tabla de modelamiento de resultados (factores predominantes)

\begin{tabular}{lcccc}
\hline & \multicolumn{2}{c}{$\begin{array}{c}\text { Coeficientes } \\
\text { no estandarizados }\end{array}$} & \multicolumn{2}{c}{$\begin{array}{c}\text { Coeficientes } \\
\text { estandarizados }\end{array}$} \\
\cline { 2 - 5 } \multicolumn{1}{c}{} & Beta & Error típico & Beta & p-valor \\
\hline Armonía de colores & 1,63 & 0,40 & 0,27 & 0,001 \\
Contraste de colores & 1,63 & 0,39 & 0,19 & 0,009 \\
Proporcionalidad de elementos & 1,66 & 0,32 & 0,38 & 0,000 \\
Encuadres & 1,69 & 0,37 & 0,29 & 0,000 \\
Caracterización temporoespacial & 1,39 & 0,37 & 0,29 & 0,002 \\
\hline
\end{tabular}

Se observa que «Proporcionalidad de elementos» es la que más aporta a la explicación de la variación del puntaje total (Beta=0,38), seguido por «Encuadres» (Beta=0,29), "Caracterización temporoespacial» (Beta=0,29), «Armonía de colores» $(0,27)$ y «Contraste de colores» (Beta=0,19). Estos resultados se vinculan a los hallazgos de las correlaciones, en que la «Proporcionalidad de elementos» resultaba un aporte a la caracterización, asimismo respecto de la importancia de los «Encuadres» para la «Caracterización de personajes» y «Equilibrio visual».

\section{Discusión}

Los antecedentes teóricos revisados permiten reafirmar la pertinencia de incluir la alfabetización visual como un aprendizaje clave dentro de la escolarización, entendiendo que los aspectos formales del lenguaje visual (p. e. color, proporcionalidad, encuadre) son contenidos enseñables y aprendibles. Esta mirada, en que «lo visual» toma el estatuto de lenguaje, favorecería el desarrollo de habilidades perceptivas, mejorando la codificación y decodificación de textos multimodales, tanto en aquellas asignaturas generalmente 
vinculadas a las artes como en las distintas disciplinas. Siguiendo el mismo argumento, existe coincidencia entre los autores en explicitar la importancia de la alfabetización visual de manera transversal en los distintos niveles del sistema educativo. Es así como se recomienda el desarrollo de experiencias informadas (Csikszentmihalyi, 1990), basadas en la relación práctica con imágenes, de manera tal que junto con el aprendizaje de los códigos se promueva la conexión del sujeto con sensaciones, emociones y sentimientos.

Complementariamente, los antecedentes recopilados en este estudio invitan a rescatar el potencial visual, estético y cultural que tienen las ilustraciones como textos visuales dentro de los cuentos ilustrados. En específico, resalta el papel que tiene el dominio de los componentes del lenguaje visual en los procesos de codificación y decodificación de las ilustraciones para la formación del lector literario infantil en los primeros niveles del sistema educacional (Educación Preescolar y Educación Básica). En este sentido, cabe precisar que en Chile se ha aumentado la dotación de cuentos ilustrados y libro álbum en las bibliotecas escolares, lo que resulta positivo; sin embargo, esto puede ser preocupante si al interactuar con las ilustraciones prosigue la tendencia a la implementación de prácticas de lectura de tipo tradicionales, con énfasis en la monomodalidad y el lenguaje verbal (Maldonado-Fuentes, Sandoval-Rubilar y Rodríguez-Alveal, 2018). Esto invita a profundizar en estudios que den cuenta cómo los docentes se están haciendo cargo de brindar oportunidades pedagógicas para el aprendizaje e integración de «lo visual» en las instancias de lectura «multimodales».

En cuanto a los resultados del estudio empírico, la evaluación auténtica de las ilustraciones elaboradas por los estudiantes en FID permitió identificar logros diferenciados en el manejo de los componentes formales del lenguaje visual (representación visual, color y composición). De ellos, se destaca la proporcionalidad de elementos como un aspecto clave, que correlaciona significativamente de manera directa con la caracterización de personajes y pertinencia; evidenciándose también el color como un factor que incide en el resultado. A nivel de hipótesis, el aporte que tienen estos elementos podría estar relacionado con la temática de las imágenes analizadas, dado que la mayoría de los textos evaluados se caracterizaron por incluir personajes animales o seres humanos que se desenvolvían en ambientes cotidianos o en paisajes naturales, creados en la lógica del mundo real y/o maravilloso. Estos hallazgos invitan a reflexionar sobre el tipo de ilustraciones de los cuentos, dado que es sabido que los niños tienden a exigir realismo en las representaciones, de manera que las imágenes coincidan con el concepto mental que tienen de los objetos. 
Por otro lado, los resultados instan a profundizar sobre las ideas previas que han construido los futuros profesores respecto de cuál es el abanico de universos posibles de considerar al momento de trabajar con las ilustraciones de un cuento. En este sentido, una limitación del presente estudio radica en no haber podido modelar si la incidencia de los factores evaluados resulta ser igual o diferente, por ejemplo, si se hubiera trabajado con ilustraciones alusivas a realidades fantásticas u oníricas. Para ello, se sugiere contar previamente con una tipificación de los textos (unidades de análisis) en función de la categoría «tipo de mundo».

En particular, llama la atención el resultado obtenido en el manejo del color, mencionado como "poco requerido" por los propios sujetos al inicio de las actividades. Tal como se observa en los resultados, tras la intervención pedagógica realizada, el color ocupó el segundo lugar en la evaluación formativa (logro promedio de 67,4\%). Cabe puntualizar que el tema del color fue enseńado desde la teoría de las emociones, siguiendo a Plutchik (1984), lo cual podría haber influido en el modelo estadístico. $\mathrm{Al}$ respecto, resulta de interés considerar que el color es uno de los elementos claves de los libros ilustrados; lo que invita a revisar con mayor detención las experiencias de aprendizaje que han tenido los estudiantes de FID respecto del uso del color en su historia escolar.

\section{Conclusiones}

En primer lugar, se concluye que el diseño metodológico efectuado permitió medir el impacto de los componentes formales del lenguaje visual en la elaboración de ilustraciones según lo estipulado. En particular, a partir de resultados empíricos, se visualizan el color, la composición y la representación visual como factores predominantes que pueden ser la base de una evaluación ponderada de dichos aspectos. En otras palabras, se pueden inferir indicadores para el diseño de una rúbrica referida a contenidos propios del lenguaje visual, lo cual sería ventajoso desde el punto de vista de la evaluación auténtica y retroalimentación en torno al dominio del lenguaje visual. Este aspecto resulta novedoso en relación con la problemática investigada, dado que se relaciona con aprendizajes en alfabetización visual, en cuyo ámbito los futuros profesores han sido escasamente evaluados. Para futuras aplicaciones, se sugiere ampliar el número de sujetos, de manera tal que se capture mayor representatividad de la población de estudiantes en FID a nivel país.

En segundo lugar, cabe señalar que el estudio empírico se ejecutó teniendo como unidades de análisis a textos cuyas ilustraciones fueron evaluadas por medio de una pauta específicamente elaborada para tales efectos. 
Un aspecto positivo de la medición fue el cuidado que se tuvo para cumplir con parámetros psicométricos de confiabilidad y validez, dado que «son cualidades esenciales que deben tener todas las pruebas o instrumentos de carácter científico para la recogida de datos» (Pérez, 2002, p. 71). Esto permitió contar con una primera versión de esta Pauta de Evaluación Alfabetización Visual, en coherencia con el propósito general de analizar el desempeño de los sujetos. No obstante, se recomienda volver a aplicar en grupos similares, para mejorar la robustez psicométrica del instrumento.

Asimismo, ha sido factible determinar que los sujetos del grupo de estudio alcanzan resultados más bien descendidos en el uso de elementos formales del lenguaje visual, dado que no superan el $78 \%$ de logro promedio en ninguno de los criterios evaluados. Este hallazgo resulta preocupante al tratarse de futuros profesionales que atenderán a alumnos de Educación Inicial y Educación Básica en el sistema escolar. Dicho antecedente coincide con la preocupación del Consejo Nacional de la Cultura y las Artes (CNCA) (2014), quienes han podido constatar que «la formación que reciben actualmente los docentes de enseñanza básica en materias de educación artística es débil y en muchos casos ausente» (2014, p. 17). A una conclusión similar llegan Brodsky y Negron (2016) al declarar que «un 70\% de las carreras de Pedagogía en Educación Básica cuentan con dos y menos cursos vinculados a las áreas artísticas» (p. 33), cuyas asignaturas responden a una formación general de tipo introductorio.

Lo anterior, podría estar asociado al énfasis colocado en el último tiempo en la medición del rendimiento como principal evidencia de la calidad de la educación, que ha tenido alto impacto en la cultura evaluativa escolar, focalizado la atención en las áreas de Lenguaje, Matemática y Ciencias. Al respecto, Errázuriz (2015) precisa que «necesitamos una educación que evidencie de un modo más consistente su vocación cultural, que sea estéticamente más interesante» (p. 87), destacando los planteamientos de Eisner (2002), quien proponía un abanico más amplio de intereses para determinar los indicadores asociados a la calidad.

Finalmente, los resultados invitan a reflexionar sobre las renovaciones curriculares de los programas de FID y las distintas carreras de pedagogía en cuya formulación cabe la posibilidad de discutir acerca de la importancia que tiene la evaluación de la alfabetización visual asociada al perfil de los profesionales de la educación. En este sentido, se recomienda hacer un seguimiento y monitoreo de estos aprendizajes en los distintos momentos de desarrollo profesional docente, incorporando prácticas de evaluación formativa para el mejoramiento de los aprendizajes en este ámbito. 


\section{Agradecimientos}

Los autores agradecen a la Dirección del Departamento de Comunicación Visual de la Facultad de Arquitectura, Construcción y Diseño de la Universidad del Bío-Bío por la participación de académicos de esta unidad en la experiencia pedagógica documentada, cuya ejecución inicial se realizó con apoyo de un fondo de desarrollo docente 2015-2016.

\section{REFERENCIAS BIBLIOGRÁFICAS}

Ahumada, P. (2005). La evaluación auténtica: un sistema para la obtención de evidencias y vivencias de los aprendizajes. Perspectiva Educacional, Formación de Profesores, 45, 11-24.

Anijovic, R. y González, C. (2013). Evaluar para aprender. Conceptos e instrumentos. Buenos Aires: Aique Educación.

Borges, M. (2012). El papel de la ilustración en la alfabetización visual. Creative processes and childhood-oriented cultural discourses, 268-272. https://doi. org/10.5151/edupro-aivcipe-51

Brodsky, J. y Negrón, B. (2016). Agenda Trama. Recomendaciones para el desarrollo de las Artes en Chile. Santiago, Chile: Edición Proyecto Trama.

Csikszentmihalyi, M (1990). Finding Flow: The Psychology of Optimal Experience. Nueva York: Harper and Row.

Cisternas, T. (2011). La investigación sobre formación docente en Chile: territorios explorados e inexplorados. Calidad en la Educación, 35, 131-164.

Colomer, T. (2010). Introducción a la literatura infantil y juvenil actual. Madrid: Síntesis.

Comellas, M. (2000). La formación competencial del profesorado: formación continuada y nuevos retos organizativos. Revista Educar, 27, 87-101.

Consejo Nacional de la Cultura y las Artes (CNCA). (2014). Estudio comparado sobre enseñanza de las artes en programas de formación en Pedagogía Básica $y$ las bases curriculares de $1^{\circ}$ a $6^{\circ}$ básico de Artes Visuales y Música. Santiago.

Correa, J. (2015). ¿Cómo aprendes a ser maestra? TIC, género y narrativas visuales de futuras maestras de educación infantil. REIRE, Revista d'Innovació $i$ Recerca en Educació, 8(2), 256-268.

Cuervo Díez, M. (2012). El poder del color, la influencia de los colores en el consumidor (Tesis de grado). Universidad de León, León, España.

Dondis, D. (2007). La sintaxis de la imagen, Introducción al alfabeto visual. Colección de Comunicación Visual. Barcelona: Gustavo Gili. 
Eisner, E. (2002). Ocho importantes condiciones para la enseñanza y el aprendizaje de las artes visuales. Revista Arte, Individuo y Sociedad, 6(12), 47-55.

Errázuriz, L. (2015). Calidad estética del entorno escolar: el (f) actor invisible. Arte, Individuo y Sociedad, 27(1), 1-100.

Farías, M. y Araya, C. (2014). Alfabetización visual crítica y educación en lengua materna: estrategias metacognitivas en la comprensión lectora de textos multimodales. Colombian Applied Linguistics Journal, 16, 93-104. https:// doi.org/10.14483/udistrital.jour.calj.2014.1.a08

Ferreras, J. y Vergilio, L. (2008). A vueltas con la alfabetización visual: lenguaje y significado en las películas de Wes Anderson. Revista Cientifica de Información y Comunicación, 1, 248-287.

García, R. (2018). La formación audiovisual del profesorado de Primaria. Treball Final de Grau en Mestre o Mestra d'Educació Primària. Universitat Jaume I.

García, M. y Benítez, M. (1998). Formación de profesores en alfabetización audiovisual. Comunicar, (11), 202-207. https://doi.org/10.3916/C11-1998-31

González, S. (1991). Percepción, imagen pictórica y niveles de descripción. Arte, Individuo y Sociedad, (4), 77-94.

Hernández, F. (2009). Educar a través de las artes desde los alfabetismos múltiples: una experiencia en formación docente. Revista Educación y Pedagogía, 21(55), 43-54.

Holzschlag, M. (2002) Color para sitios web. México D.F.: MacGraw-Hill Interamericana Editores S.A.

Maldonado-Fuentes, A., Sandoval-Rubilar, P. y Rodríguez-Alveal, F. (2018). Evaluación de comprensión lectora y libro álbum en estudiantes de Formación Inicial Docente. Revista de la Escuela de Ciencias de la Educación, 1(13), 65-84. https://doi.org/10.35305/rece.v1i13.325

Meo, A. (2010). Consentimiento informado, anonimato y confidencialidad en investigación social. La experiencia internacional y el caso de la sociología en Argentina. Aposta. Revista de Ciencias Sociales, 44, 1-30.

Ministerio de Educación de Chile (Mineduc) (2018). Bases curriculares primero a sexto básico. Santiago, Chile. Recuperado de https://www.curriculumnacional.cl/614/articles-22394_programa.pdf

Nunnally, J. (1987). Teoría psicométrica. México: Trillas.

Ospina, C. (2011). El libro álbum: lecturas y lectores posibles (Tesis de magíster en Educación). Universidad Nacional de Colombia, Bogotá.

Pagliarulo, E. (2013). La importancia de la alfabetidad visual en la formación docente. Actas del Congreso Iberoamericano de las Lenguas en la 
Educación: las lenguas en la educación, cine, literatura, redes y nuevas tecnologías (pp. 105-116).

Pérez, G. (2002). Investigación cualitativa. Retos e interrogantes: Volumen II. Técnicas y análisis de datos. Madrid: La Muralla.

Pina, B. (2001). Nuevas tecnologías en educación: preparando para un nuevo modo de conocer. En F. Blázquez (Coord.), Sociedad de la información y educación. Mérida: Junta de Extremadura.

Plutchik, R. (1965). La naturaleza de las emociones. Revista de Psicología General y Aplicada: Revista de la Federación Española de Asociaciones de Psicología, 20(76), 5-13.

Plutchik, R. (1984). Emotions: A general psychoevolutionary theory. Approaches to emotion, 197-219.

Rowden, M. (2003). El arte de la identidad. México: Mc Graw Hill.

Salisbury, M. y Styles, M. (2014). El arte de ilustrar libros infantiles: concepto y práctica de la narración visual. Barcelona: Art Blume.

Sánchez Ruiz, D. (2017). Educación artística y alfabetización visual. Un estudio de caso en la formación inicial del profesorado de Educación Primaria (Tesis doctoral). Universidad de Málaga.

Sautu, R., Boniolo, P., Dalle, P. y Elbert, R. (2005). Manual de metodología. Construcción del marco teórico, formulación de los objetivos y elección de la metodología. Buenos Aires: Consejo Latinoamericano de Ciencias Sociales - Clacso.

Villa Orrego, N. (2008). Propuesta de alfabetización visual para estudiantes de Educación Básica apoyada en recursos hipermediales. Revista Interamericana de Bibliotecología, 31(1), 207-225.

Wong, W. (1998). Fundamentos del diseño. Barcelona: Gustavo Gili. 